\title{
Sexing Frogs by Real-Time PCR: Using Aromatase (cyp19) as an Early Ovarian Differentiation Marker
}

\author{
L. Navarro-Martín ${ }^{a} \quad$ Y.M. Velasco-Santamaría a, c P. Duarte-Guterman ${ }^{a}$

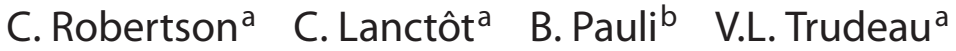 \\ ${ }^{a}$ Centre for Advanced Research in Environmental Genomics, Department of Biology, University of Ottawa, and \\ bEnvironment Canada, National Wildlife Research Center, Carleton University, Ottawa, Ont., Canada; \\ 'Research Group on Reproduction and Toxicology of Aquatic Organisms - GRITOX, Institute of Aquaculture, \\ Faculty of Agropecuary Sciences and Natural Resources, University of the Llanos, Villavicencio, Colombia
}

\section{Key Words}

Aromatase · cyp17 • cyp19 • foxl2 · Gene expression • Lithobates (Rana) sylvaticus • Sexual differentiation • Silurana (Xenopus) tropicalis · Tadpoles $\cdot$ Wood frog

\begin{abstract}
Most anurans have no identified sex-markers; therefore, alternative methods for identification of early changes in sex ratios are required. In this study, Lithobates sylvaticus and Silurana tropicalis tadpoles were sampled at different developmental stages covering the entire process of sex differentiation. Three candidate genes known to be involved in sex differentiation in other vertebrate species were selected to develop a method to identify phenotypic sex in frogs: cytochrome p450 aromatase (cyp19), forkhead box L2 (foxl2) and the cytochrome 17-alpha-hydroxylase/17,20 lyase (cyp17). Cloning of these genes revealed nucleotide identity values ranging between $75-97 \%$ when compared to other amphibian species. Gene expression of cyp17, cyp19 and fox/2 in L. sylvaticus adult gonads and gonad-mesonephros complex (GMC) of tadpoles was analyzed by real-time RT-PCR. Results showed clear sexually dimorphic patterns in the expression
\end{abstract}

of the 3 genes. Our analysis reveals that GMC gene expression levels of cyp19 alone can be used as a robust predictor of phenotypic sex in L. sylvaticus tadpoles. In addition, we validated this method measuring cyp19 mRNA levels in $S$. tropicalis GMCs. We propose measuring cyp19 as a tool to study the effects of chemical contaminants (including endocrine disrupting compounds) on amphibian gonadal development and sex ratios in the future.

Copyright $\odot 2012$ S. Karger AG, Base

In many non-mammalian vertebrates, gonadal development is under the direct influence of steroidogenic enzymes, sex steroids and environmental factors [Bogart, 1987; Scherer, 1999]. Further, sex differentiation in amphibians, fish, reptiles, and birds is a sensitive period that can be altered by exposure to exogenous hormones and endocrine disrupting chemicals [Boggs et al., 2011; Flament et al., 2011; Norris, 2011; Ottinger et al., 2011; PaulPrasanth et al., 2011; Vajda and Norris, 2011; Warner, 2011]. In contrast, sex steroids are considered as gonadal hormones, which are synthesized as a result of gonadal sex differentiation in mammals. Sex steroids act to estab-

\section{KARGER}

Fax +4161306 1234

E-Mail karger@karger.ch

www.karger.com (c) $2012 \mathrm{~S}$. Karger AG, Basel

$1661-5425 / 12 / 0066-0303 \$ 38.00 / 0$

Accessible online at:

www.karger.com/sxd
Dr. Laia Navarro-Martín

Department of Biology, Centre for Advanced Research in Environmental Genomics University of Ottawa, 30 Marie Curie, Gendron \#163

Ottawa, ON K1N 6 N5 (Canada)

E-Mail laianavarromartin@gmail.com 
lish the secondary sexual phenotype in most mammalian species [vom Saal, 1989]. In teleost fish, it is the ratio of intragonadal androgens and estrogens during the period of sex differentiation that drives the formation of the ovary versus the testis [Baroiller and D'Cotta, 2001], rather than the action of a single steroid. Generally, gonadal steroidogenesis is active before clear histological differentiation in many non-mammalian vertebrates. For example, as it has been demonstrated in chickens [Scheib, 1983] and turtles [Dorizzi et al., 1991], estrogens are synthesized by morphologically undifferentiated female gonads in frogs [Isomura et al., 2011]. This demonstrates that sex steroids also play an important role in frog sex differentiation.

Studies published in the last decade have reported sexually dimorphic expression of several genes suspected to be involved in frog sex determination and differentiation in tadpoles gonad-mesonephros complex (GMC). The majority of these have focused on a single species, Glandirana (Rana) rugosa [Takase et al., 2000a, b; Sugita et al., 2001; Shibata et al., 2002; Aoyama et al., 2003; Ohtani et al., 2003; Oshima et al., 2005, 2006, 2007, 2008, 2009; Yamamura et al., 2005; Iwade et al., 2008; Maruo et al., 2008; Nakamura et al., 2008; Sakurai et al., 2008; Yokoyama et al., 2009; Isomura et al., 2011; Suda et al., 2011a, b]. In this frog species, both genetic and phenotypic sex can be determined [Miura et al., 1998], and gene expression levels in differentiating GMCs can be studied separately in genetic males and females. GMC gene expression patterns during sex differentiation have only been studied in a few other frog species, including Xenopus laevis [Semba et al., 1996; Koyano et al., 1997; Takase et al., 1999; Nakajima et al., 2000; Kawano et al., 2001; Lutz et al., 2001; Akatsuka et al., 2005; Osawa et al., 2005; Yoshimoto et al., 2006, 2008; Urbatzka et al., 2007, 2010; Okada et al., 2009], Silurana (Xenopus) tropicalis [El Jamil et al., 2008a; Duarte-Guterman and Trudeau, 2011], Engystomops (Physalaemus) pustulosus [Duarte-Guterman et al., 2012] or Lithobates catesbeianus (formerly Rana catesbeiana) [Mayer et al., 2002]. In these reports, 3 genes have consistently exhibited sexually dimorphic expression patterns in gonads of adult frogs and differentiating tadpoles. These are the cytochrome $\mathrm{P} 450$ aromatase gene (cyp19) that encodes for aromatase, the enzyme responsible for controlling the conversion of androgens into estrogens; the transcription factor forkhead box L2 (foxl2) that positively regulates cyp 19 transcription; and the cytochrome P450 17-alpha-hydroxylase/17,20-lyase (cyp17) that encodes for the enzyme responsible for controlling the conversion of progestagens for androgen production.
The wood frog, L. sylvaticus (formerly Rana sylvatica), is a common and abundant species in northern North America. Sex differentiation in wood frogs is typical for a differentiated gonochoristic species, with undifferentiated gonads developing towards ovaries or testes before metamorphosis is complete [Witschi, 1929]. As shown in other species from the Ranidae family, the course of sex differentiation in wood frogs can be altered by the administration of exogenous hormones [Mackenzie et al., 2003]. However, to our knowledge gene expression profiles of key genes involved in wood frog gonadal differentiation have not been studied previously. For this reason, one of the objectives of the present study was to clone and characterize wood frog cyp19, foxl2 and cyp17 genes. On the other hand, phenotypic sex identification in frogs has been traditionally achieved by histological approaches, which is time consuming and requires samples from late development stages. In addition, when phenotypic sex is evaluated by histological procedures, no tissue typically remains for molecular studies. For these reasons, we identified the need to develop a molecular tool that allows sex identification and determination of sex ratios in populations and, at the same time, permits the study of the mechanisms involved. Given the sexually dimorphic expression patterns in the tadpole GMC of other frog species, and due to their importance in controlling sex steroid production, we hypothesized that the combined expression pattern of cyp19, foxl2 and cyp17 could be a useful early marker of sex differentiation in L. sylvaticus. We aimed to identify molecular markers for phenotypic sex that could be used more generally in amphibian species, so we have also studied the African frog, S. tropicalis. We believe that our approach represents a useful tool to both determine phenotypic sex ratios at early stages of development as well as to analyze the effects of exposure to endocrine disrupting chemical contaminants during frog differentiation in future studies.

\section{Materials and Methods}

\section{Animals and Sample Collection}

Wild adult $L$. sylvaticus frogs ( 3 males and 3 females) were collected at the Long-term Experimental Wetlands Area at the Canadian Forces Base Gagetown, N.B. Brains, kidneys and gonads were dissected in the laboratory and stored at $-80^{\circ} \mathrm{C}$ until further analysis. In addition, L. sylvaticus tadpoles were collected in the same area from a natural pond at 4 different sampling times during spring 2009. Collections were made when the animals reached a determinate median Gosner developmental stage (Gs) [Gosner, 1960]: Gs26 ( $\mathrm{n}=16), \mathrm{Gs} 28(\mathrm{n}=16)$, Gs30 $(\mathrm{n}=15)$, and Gs31-42 
Table 1. Primers and tissues used for gene cloning

\begin{tabular}{|c|c|c|c|}
\hline Gene & Forward primer & Reverse primer & Tissue \\
\hline cyp19 & 5' -TGGATTAATGGCGAGGAAAC-3' & 5'-GGYTGGTACCTCATGCTTTCA-3' & Ovary \\
\hline foxl2 & 5'-ATGGCWATYMGGGARAGYBC-3' & 5'-TAKGGRCTGTAGGAGGACGA-3' & Brain \\
\hline cyp 17 & 5'-AGTTTCACCGCAAAATGGTC-3' & 5'-TATGCMACAGCCCATTTCAA-3' & Brain \\
\hline
\end{tabular}

( $n=52$ ). In the case of Gs26, 28 and 30, the median Gs was targeted during the collections, with all tadpoles collected at the same stage as the median stage of the pond. However, later in development, the variability of stages found in natural ponds increases, and we observed tadpoles from a broad range of stages at any given time. For that reason, in the case of the Gs31-42 sampling, although the animals collected had the same age (were sampled the same day), developmental stages ranged from Gs31-42. Animals were euthanized with MS-222 (Sigma) prior to collections. A ventral incision was made in tadpoles prior to preserved in RNAlater solution (Ambion) at ambient air temperature for $<12 \mathrm{~h}$. Tadpoles were then stored at $4^{\circ} \mathrm{C}$ for 3 days, before the GMC was removed and stored at $-80^{\circ} \mathrm{C}$ until further analysis. This sampling methodology was previously optimized in our laboratory to ensure RNA quality [Navarro-Martín et al., 2012]. The GMC was chosen for ease of dissection and to ensure sufficient amounts of mRNA when studying gonadal differentiation in tadpoles. Some other examples of this approach are available [Urbatzka et al., 2007; Duarte-Guterman and Trudeau, 2011; DuarteGuterman et al., 2012]. All procedures followed approved animal care protocols of the University of Ottawa and the Canadian Council on Animal Care.

Cloning of L. sylvaticus Genes Involved in Vertebrate Gonadal Differentiation

Total RNA was isolated from different tissues obtained from adult wood frogs (table 1) using TRIzol, as described by the manufacturer (Invitrogen). The RNA extracted was then resuspended in RNase-free water and stored at $-80^{\circ} \mathrm{C}$. Five micrograms of total RNA were reverse transcribed to cDNA using Superscript II and $200 \mathrm{ng}$ of random hexamer primers following the manufacturer's instructions. The resulting cDNA was used to amplify the desired genes using native Taq DNA polymerase (Invitrogen) and the respective primers (table 1). In order to obtain the sequence of the desired genes, design of primers based on conserved areas of other frog species sequences was required. Primers were designed using Primer 3 (http://fokker.wi.mit.edu/primer3/input.htm). The PCR cycling conditions were: $2 \mathrm{~min}$ at $95^{\circ} \mathrm{C}$; 40 cycles of $45 \mathrm{~s}$ at $95^{\circ} \mathrm{C}, 30 \mathrm{~s}$ at $54^{\circ} \mathrm{C}, 45 \mathrm{~s}$ at $72^{\circ} \mathrm{C}$ and a final extension of 10 min at $72^{\circ} \mathrm{C}$. PCR products of each sample were resolved on $1 \%$ agarose gel stained with ethidium bromide. When the amplified product was not evident or the band was very faint, the expected size was sliced from the gel, and the sample was purified using QIAquick Gel extraction kit (Qiagen). Subsequently, the purified product was re-amplified using the same PCR cycling conditions described above. PCR products were cloned into pCR2.1-TOPO vector and transformed into E. coli Topol0 Chemically Competent cells (Invitrogen). Three individual clones per each gene were sequenced. Obtained sequences were submitted to Genbank. BLAST (http://www.ncbi.nlm.nih.gov/BLAST) was used to check for nucleotide identity with other frog and toad species (online supplementary table 1; for all supplement material see www. karger.com/doi/10.1159/000343783).

\section{Identification of Molecular Markers to Determine}

Phenotypic Sex in L. sylvaticus

RNA Extractions and cDNA Synthesis. Total RNA was isolated from adult kidneys and gonads using RNeasy Mini Kit (Qiagen) and from the tadpoles' GMCs using the RNeasy Micro Kit (Qiagen). In all cases, an RNase-free DNase treatment was performed during the extractions. All procedures were carried out following manufacturer's protocols. Total RNA was resuspended in RNasefree water. Concentrations of total RNA, the absorbance ratios at 260 and $/ 280 \mathrm{~nm}$, and at 260 and /230 nm were determined using the NanoDrop 1000 Spectrophotometer (NanoDrop Technologies Inc.). The RNA integrity number determined using the Agilent 2100 Bioanalyzer, was used to assess RNA quality. All quality parameters were optimal (ratios of absorbance around 2 and RNA integrity numbers $\geq 7$ ). Samples were stored at $-80^{\circ} \mathrm{C}$ until further analysis. Total cDNA tissues were synthesized from $1 \mu \mathrm{g}$ of total RNA, using $200 \mathrm{ng}$ random hexamer primers (Invitrogen) and Superscript II reverse transcriptase (Invitrogen). Due to the small amount of RNA used, the incubation period at $42^{\circ} \mathrm{C}$ was increased from $50 \mathrm{~min}$ to $1.5 \mathrm{~h}$ during CDNA synthesis.

Real-Time RT-PCR Analysis for L. sylvaticus cyp19, foxl2, cyp17, and rpl8. Based on the L. sylvaticus sequences obtained, genespecific primers (table 2) were developed using Primer3 (http:// frodo.wi.mit.edu/primer3/input.htm). Gene location, size, and melting temperatures for each amplicon are summarized in table 2 . In addition, a partial sequence of $L$. sylvaticus rpl8 gene has been previously characterized in our laboratory (Genbank accession number HQ630611) and real-time RT-PCR reactions optimized [Navarro-Martín et al., 2012]. The lack of amplification in control samples not subjected to reverse transcriptase indicated the absence of genomic DNA contamination. SYBR Green I chemistry was used, and a dissociation curve indicating the presence of a single amplification product was performed for each primer pair to verify primer specificity. The identity of the amplicons was further confirmed by sequencing. For each gene, primer concentrations were optimized to ensure maximum amplification and relative standard curves that yielded an efficiency of 100 $\pm 10 \%$ (slope between -3.1 and -3.6 ) and $r^{2}>0.985$, according to the manufacturer's instructions (MX3000P real-time polymerase chain reaction system; Stratagene). Standard curves were generated using a serial dilution of cDNA mix from all samples and stages analyzed. 
Table 2. Real-time RT-PCR primer sets and conditions for L. sylvaticus

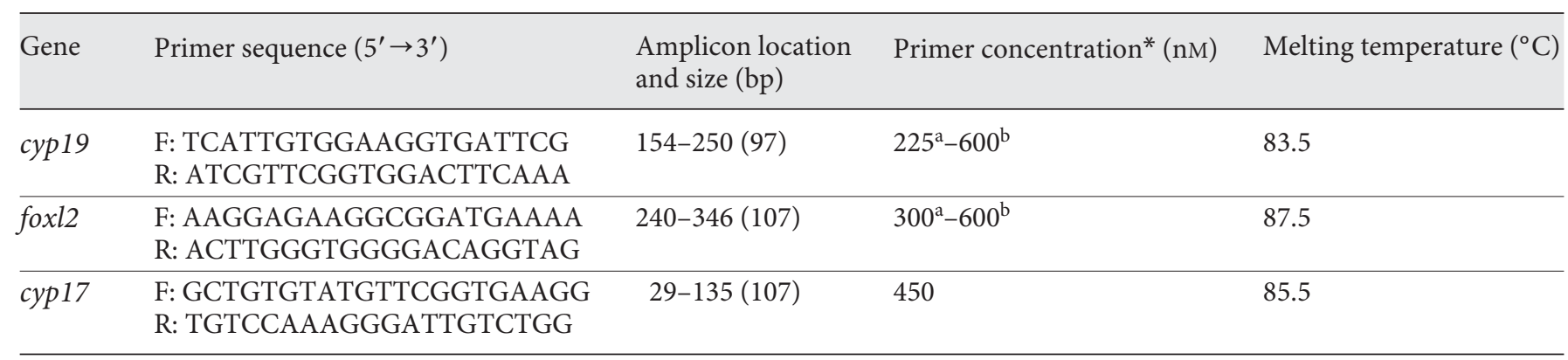

* To obtain optimized conditions for the real-time RT-PCR reactions, different primer concentrations were used in the different tissues. ${ }^{a}$ Primer concentrations used in the reactions containing adult gonads and kidneys as well as GMC from tadpoles at developmental Gs36-41. ${ }^{b}$ Primer concentrations used in the reactions containing GMC from tadpoles at developmental Gs26, 28 and 30.

Each sample was run in duplicate in optically clear 96-well plates in a final volume of $25 \mu \mathrm{l}$. For every gene and PCR run, nontemplate and non-reverse transcriptase controls were included to confirm the absence of contamination. In all cases, each PCR reaction contained: adult kidney, adult gonad or tadpole GMC cDNA (15.63 or $6.25 \mathrm{ng}$ of RNA transformed to cDNA in adults tissues or in the tadpole GMCs, respectively), $1 \times$ Q-PCR buffer (Qiagen), $2.5 \mathrm{mM} \mathrm{MgCl}_{2}$ (Qiagen), $200 \mu \mathrm{M}$ dNTPs (Invitrogen), $100 \mathrm{nM}$ passive reference dye (Stratagene), and $1.25 \mathrm{U}$ HotStarTaq (Qiagen). An optimized concentration for each primer set (see table 2) and $0.25 \times$ SYBR Green I Dye (Molecular Probes) were added to the reaction. Cycling parameters for foxl2, cyp17 and $r p l 8$ were as follows: activation step at $95^{\circ} \mathrm{C}$ for $15 \mathrm{~min}$ followed by 40 cycles of $95^{\circ} \mathrm{C}$ for $15 \mathrm{~s}, 60^{\circ} \mathrm{C}$ for $5 \mathrm{~s}, 72^{\circ} \mathrm{C}$ for $54 \mathrm{~s}$ and $81^{\circ} \mathrm{C} 18 \mathrm{~s}$. In the case of cyp19, optimal cycling parameters were as follows: activation step at $95^{\circ} \mathrm{C}$ for $15 \mathrm{~min}$ followed by 40 cycles of $95^{\circ} \mathrm{C}$ for $30 \mathrm{~s}, 60^{\circ} \mathrm{C}$ for $1 \mathrm{~min}$ and $72^{\circ} \mathrm{C}$ for $1 \mathrm{~min}$. Finally, a temperature-determining dissociation step was performed at the end of the amplification phase to ensure the presence of a single amplified product.

\section{Validation of the Identified Phenotypic Sex Markers in}

Frogs Using S. tropicalis

S. tropicalis was chosen as a second species to validate our phenotypic sex marker method. Gene expression profiles of cyp19 levels in GMCs of S. tropicalis tadpoles from Nieuwkoop and Faber (NF) [Nieuwkoop and Faber, 1994] developmental stages NF52-66, and adult gonads were described by Duarte-Guterman and Trudeau [2011]. Compared to the earlier study, the present study includes earlier developmental stages, including NF48 and 50. In addition, sample size for developmental stages NF52 and 54-55 was increased. In Duarte-Guterman and Trudeau [2011], cyp19 did not amplify in some of the samples, and we suspect this was due to some detection limitations of the technique used. In the previous study, multiplex real-time RT-PCR reactions were carried out, where different primers compete to amplify different genes in the same reaction. For that reason, we decided also to include and re-analyze some of the samples from the previous study (developmental stages NF52, 55 and 60, and adult testis and ovaries). To avoid detection limitations and to improve amplifica- tions, the present study was done using single real-time PCR reactions (described below).

Sample Collection, RNA Extractions and cDNA Synthesis for $S$. tropicalis. Collection and dissection of GMCs at developmental stages NF48 $(\mathrm{n}=16)$, NF50 $(\mathrm{n}=16)$, NF52 $(\mathrm{n}=8)$, and NF54 $(\mathrm{n}=8)$ were previously done using the same breeding batch described by Duarte-Guterman and Trudeau [2011]. Samples were stored at $-80^{\circ} \mathrm{C}$ until further analysis. Total RNA was obtained using the RNeasy Micro Kit (including the DNase treatment set; Qiagen). All samples were reverse transcribed to cDNA using $1 \mu \mathrm{g}$ of RNA, $200 \mathrm{ng}$ random hexamers and Superscript II reverse transcriptase (Invitrogen). In addition, cDNA from tadpoles GMCs obtained by Duarte-Guterman and Trudeau [2011] at the developmental stages NF52 $(n=8), \operatorname{NF} 55(n=8)$ and NF60 $(\mathrm{n}=16)$, and adult gonads ( $\mathrm{n}=6$ ovaries and $\mathrm{n}=6$ testis) were used. In summary, a total of 12 adult gonads and 80 GMCs were analyzed from $S$. tropicalis tadpoles (NF48 $(\mathrm{n}=16)$, NF50 $(\mathrm{n}=$ $16)$, NF52 $(n=16), \operatorname{NF} 54-55(n=16)$, and NF60 $(n=16)$ in the present study.

Real-Time RT-PCR Analysis for S. tropicalis cyp19. To analyze cyp19 levels in the $S$. tropicalis samples, the same gene-specific primers designed by Duarte-Guterman and Trudeau [2011] were used in a single PCR reaction. Each sample was run in duplicate in optically clear 96-well plates with a final volume of $25 \mu \mathrm{l}$. The lack of amplification in the control samples, including non-template and non-reverse transcriptase controls, were included to confirm the absence of contamination. Each PCR reaction contained: 6.25 ng of RNA transformed to cDNA, $1 \times$ Q-PCR buffer (Qiagen), $2.5 \mathrm{mM} \mathrm{MgCl}_{2}$ (Qiagen), $200 \mu \mathrm{M}$ dNTPs (Invitrogen), $100 \mathrm{nM}$ passive reference dye (Stratagene), and 1.25 U HotStarTaq (Qiagen). The optimized concentration of $325 \mathrm{nM}$ of the primer set was added to the reaction. Cycling parameters were as follows: activation step at $95^{\circ} \mathrm{C}$ for $10 \mathrm{~min}$ followed by 40 cycles of $95^{\circ} \mathrm{C}$ for $30 \mathrm{~s}, 60^{\circ} \mathrm{C}$ for $1 \mathrm{~min}, 72^{\circ} \mathrm{C}$ for $1 \mathrm{~min}$. Finally, a temperaturedetermining dissociation step was performed at the end of the amplification phase to ensure the presence of a single amplified product. The amplification curve yields an efficiency of $99.2 \%$, a slope of -3.342 and an $r^{2}$ of 0.989 . On each assay plate, standard curves were generated using a serial dilution of cDNA mix from all samples and stages analyzed. 
Statistical Analysis

To determine the best predictor(s) of phenotypic sex in L. sylvaticus tadpoles, 3 steps were followed. First, a 2-step cluster analysis (where the number of clusters was not predetermined) was performed using a combination of stage (as a categorical variable) and/or GMC cyp19-, foxl2- and cyp17-fold change gene expression levels (as continuous variables) from tadpoles of the same age. Developmental stages ranged from Gs31 to 42 . The cluster analysis produced 2 clusters, which distinguished individuals with higher and lower gene expression levels, allowing us to classify tadpoles as presumptive males and females (see results section). Second, a discriminant analysis was used to determine which predictor variables were better at discriminating presumptive males and females. Since sex ratios in frog populations are expected to be 1:1 (male:female), equal prior probabilities were assumed at the beginning of the analysis. A cross-validation method was used to calculate the average of correctly classified samples. Third, a 2-step cluster using cyp19 and foxl2 gene expression levels was carried out for L. sylvaticus GMCs from tadpoles at earlier developmental stages (Gs26, 28 and 30). We found cyp19 to be the best predictor for $L$. sylvaticus presumptive sexes (see results section). Therefore, to validate our method in S. tropicalis, cyp19 expression was used in a 2 -step cluster analysis (where the number of clusters was not predetermined) to classify presumptive males and females.

Significant differences in gene expression levels between sexes in adult frogs were also tested. First, gene expression levels between adult male and female kidneys and gonads were compared using a Student $t$ test. Since no differences were found between males and females in the adult kidneys, data from both sexes were combined. Subsequently, a one-way ANOVA test followed by a multiple comparisons Tukey's post hoc test was carried out to determine differences between adult kidneys, testes and ovaries. In addition, differences in mean gene expression among sexes were compared in Gs30 and 31-42 L. sylvaticus GMCs as well as in NF50, 52, 54-55, 60 GMCs and adult gonads from S. tropicalis. In all cases and before any analysis, normality and homoscedasticity of variances was verified using Shapiro-Wilk's and Levene's test, respectively. Differences in mean gene expression among sexes were determined by a Student's t-test. Data that violated the assumption of normality was analyzed using the Mann-Whitney test. Furthermore, association between gene expression levels of cyp19, foxl2 and/or cyp17 at Gs26, 28, 30, and 31-42 was tested in L. sylvaticus GMCs. In this case, a Pearson correlation test was performed if the data were normal; otherwise, a Spearman correlation test was performed. Statistical analyses were performed using SPSS 15.0 package. Differences were considered statistically significant when $\mathrm{p}<0.05$.

\section{Results}

\section{L. sylvaticus Genes Are Highly Conserved When}

Compared to Other Frog Species

We sequenced, partially identified and submitted to Genbank L. sylvaticus cDNA sequences of the following genes: cyp19, JX162018; foxl2, JX162019; and cyp17, JX162020. Multiple nucleotide alignments of $L$. sylvaticus sequences against sequences of other anuran species showed an expected high similarity with Rana, Glandirana and Lithobates spp. (94-97\%, online suppl. table 1), while sequence conservation was moderate when compared to Xenopus and Silurana (75-85\%, online suppl. table 1).

\section{Expression of cyp19, foxl2 and cyp17 Is Tissue- and}

Gender-Specific in L. sylvaticus Adults

Expression of cyp19 was not detected in adult male or female L. sylvaticus kidneys. Although expression of foxl2 and cyp17 was detected in male and female kidneys, no differences between sexes were observed $(\mathrm{t}=$ $-1.927, p=0.126 ; t=-1.412, p=0.231)$. For this reason, both male and female values were combined (fig. 1). Adult L. sylvaticus ovaries were characterized by having significantly higher levels of cyp19 (260-times, $\mathrm{t}=$ $10.515, \mathrm{p} \leq 0.001)$ and foxl2 (33-times, $\mathrm{t}=6.101, \mathrm{p}=$ $0.024)$ and lower levels of cyp17 (130-times, $t=-5.597$, $\mathrm{p}=0.005)$ than adult testes. When compared to testes and ovaries, foxl2 gene expression was found to be significantly lower (6 and 197-times lower, respectively) in adult $L$. sylvaticus kidneys (ANOVA, $\mathrm{F}=30.721, \mathrm{p} \leq$ 0.001 ). Kidney cyp17 levels were lower than those measured in both testes (640-times) and ovaries (5-times), but significant differences were only detected when kidneylevels where compared to testes (ANOVA, $\mathrm{F}=23.617$, $\mathrm{p} \leq 0.001)$.

\section{Gosner Stage Does Not Contribute to the Assignment} of Presumptive Phenotypic Sex in L. sylvaticus

\section{Tadpoles}

Gene expression analysis was carried out in L. sylvaticus tadpoles of the same age but with different developmental stages, ranging from $\mathrm{Gs} 31$ to $42(\mathrm{n}=52)$. A 2-step cluster analysis using a combination of stage (as a categorical variable) and cyp19, foxl2 and cyp17-fold change gene expression levels (fold change as a continuous variable) was carried out. The cluster analysis produced 2 clusters that distinguished individuals with higher and lower gene expression levels. Several studies have demonstrated that sexually differentiated tadpoles and adult frogs present sexually dimorphic gene expression patterns of cyp19, foxl2 and cyp17 in GMC tissues and adult gonads, respectively (see Introduction and Discussion sections). These studies indicated that cyp19 and foxl2 levels are upregulated in adult female gonads and differentiating female tadpole GMC, while cyp17 levels are highly expressed in adult testes or male differentiating GMCs. For this reason, in the present study individuals 


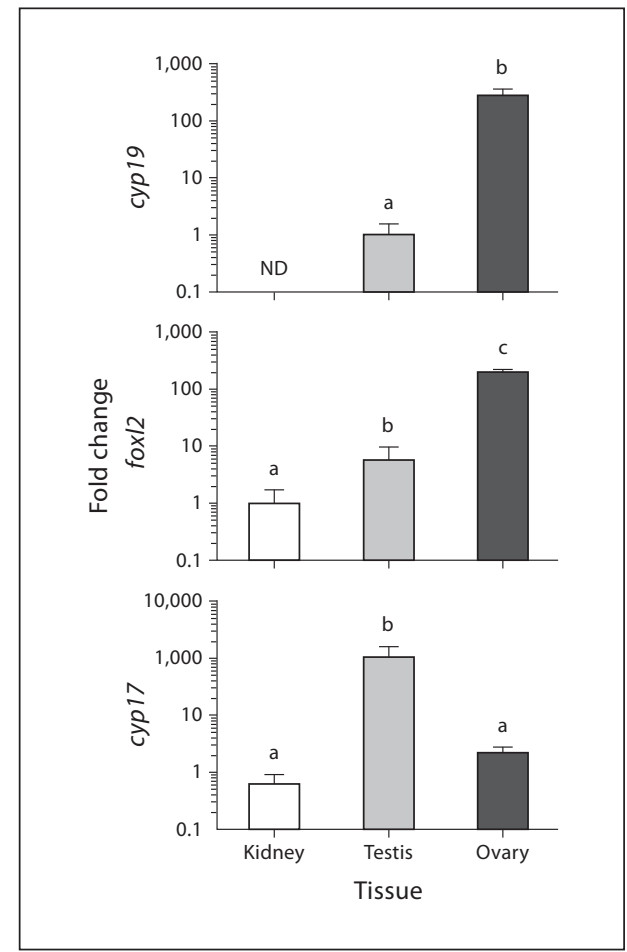

Fig. 1. L. sylvaticus adult gene expression of cyp19, foxl2 and cyp17. Data were normalized to $r p l 8$ and are presented as fold change in expression relative to the lowest sample value for each gene. Bars represent the mean \pm SEM for each tissue $(n=3$ for ovaries and testes, $\mathrm{n}=6$ for kidneys). Different letters indicate statistical differences $(p<0.05)$ after ANOVA and a multiple comparison Tukey post hoc test. ND $=$ Non-detected values.

that presented higher cyp19 and foxl2 gene expression levels, but lower cyp17 expression levels, were identified as presumptive phenotypic females, while the ones that presented the opposite pattern were identified as presumptive phenotypic males. Cluster distribution classified 27 tadpoles as presumptive females and 25 as presumptive males. The analysis also revealed that, in animals of the same age, Gosner stage did not contribute to the classification of either cluster: representation of the data by developmental stage clearly shows no difference between different Gosner stage of cyp19, foxl2 or cyp17 gene expression levels (online suppl. fig. 1). On the other hand, all data for cyp19, foxl2 and cyp17 gene expression levels contributed to the classification of both clusters. Analysis of $r p l 8$ gene expression levels revealed no differences between presumptive sexes or stages (online suppl. fig. 1).

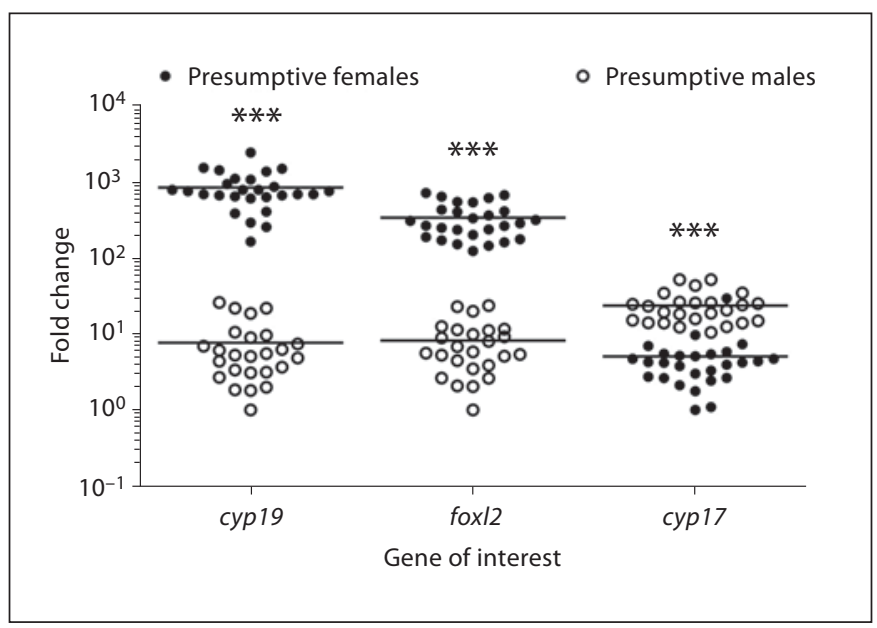

Fig. 2. Expression of cyp19, foxl2 and cyp17 in the gonad-mesonephros complex of L. sylvaticus tadpoles during late metamorphosis. Animals at various developmental stages were collected from a natural pond when the median stage in the pond was Gs36 ( $n=52$, developmental stages ranged from Gs31 to 42). Data are presented as fold change in expression relative to the lowest sample value for each gene. A 2-step cluster analysis (where the number of clusters was not predetermined) using a combination of developmental stage (as a categorical variable) and/or cyp19-, foxl2- and cyp17-fold change gene expression levels (as a continuous variable) was carried out in all cases to classify tadpoles as presumptive phenotypic males and females (see Materials and Methods and Results sections for more details). Once classified, data were analyzed by Mann-Whitney's test. Bars represent the mean for each presumptive phenotypic sex. Significance is indicated by ${ }^{* *} \mathrm{p}<0.001$.

Levels of cyp19, foxl2 and cyp17 Expression Are Sexually Dimorphic in L. sylvaticus Presumptive Phenotypic Females and Males at Late Metamorphic Stages

To be able to determine the relative importance of the variables that classify both presumptive phenotypic females and males, and to calculate significant differences between groups, a discriminant analysis was carried out using expression of cyp19, foxl2 and cyp17 for Gs31-42 GMCs as the predictor variables. Wilks' $\lambda$ values range from 0 to 1 . The smaller the $\lambda$ value, the more the predictor contributes to discriminate between the groups [Burns and Burns, 2009]. Results revealed that all predictors significantly contribute to discriminate phenotypic sex (Wilks' $\lambda=0.076, \mathrm{p}=0.000, \mathrm{~F}=604.902$ for cyp19; Wilks' $\lambda=0.102, \mathrm{p}=0.000, \mathrm{~F}=442.594$ for foxl2 and Wilks' $\lambda=$ $0.306, \mathrm{p}=0.000, \mathrm{~F}=113.663$ for $c y p 17)$. Presumptive phenotypic females expressed significantly higher levels of cyp19 and foxl2 (approximately 100-fold and 40-fold 
higher, respectively) than presumptive phenotypic males. Presumptive phenotypic females showed 5-fold lower cyp17 gene expression levels than presumptive phenotypic males (fig. 2). The high canonical correlation (eigenvalue $=30.057 ; \mathrm{r}=0.984)$ indicates that the function discriminates well between groups. In addition, Wilks' $\lambda$ indicates that the discriminant function is highly significant ( $\mathrm{p} \leq 0.001$ ) with only $3.2 \%$ of the variability not explained by the differences among groups. The structure matrix correlations are indicators of the importance of each predictor. An absolute value of 0.3 is considered the cut-off between an important versus a less important variable [Burns and Burns, 2009]. The structure matrix correlation values were $0.634,0.543$ and -0.275 for cyp19, foxl 2 and cyp17, respectively, revealing that the expression of cyp 17 is a poor predictor. The cross-validated classification showed that overall $100 \%$ were correctly classified.

\section{Dimorphic Patterns of cyp19 and foxl2 Gene}

Expression in L. sylvaticus GMC Can Be First

\section{Detected at Gs30}

Only cyp19 and foxl2 gene expression levels were analyzed in $L$. sylvaticus samples at early developmental stages (Gs26, 28, and 30) because as indicated in the previous section cyp17 gene expression levels were found to be a poor indicator of phenotypic sex. Data from animals at Gs26 and 28 were all grouped into a single cluster. In marked contrast, cluster analysis of the Gs30 samples produced 2 distinct groups. For that reason, Gs26 and 28 samples were assigned as undifferentiated tadpoles, while the 2 clusters generated from Gs30 samples were assigned as presumptive phenotypic females and males (fig. 3). At Gs30, presumptive phenotypic females exhibited $4 \times$ and $2.4 \times$ significantly higher levels than presumptive phenotypic males for GMC cyp19 $(\mathrm{t}=4.262, \mathrm{df}=13, \mathrm{p}=0.001)$ and foxl2 $(\mathrm{t}=4.066, \mathrm{df}=13, \mathrm{p}=0.003)$, respectively.

Expression Levels of cyp19, foxl2 and cyp17 Are Highly Correlated in the GMCs of Differentiated L. sylvaticus Tadpoles

Correlations between cyp19, foxl2 or cyp17 gene expression levels were determined for samples of $L$. sylvaticus at Gs31-42 (fig. 4a-c). Significant correlations ( $\mathrm{p} \leq$ 0.001 ) were found between all 3 genes. The highest correlation (Spearman's $\mathrm{r}=0.890, \mathrm{p} \leq 0.001$; fig. $4 \mathrm{a}$ ) was between cyp19 and foxl2. Gene expression levels of cyp17 showed a negative correlation with cyp19 and foxl2 (Spearman's $\mathrm{r}=-0.641, \mathrm{p} \leq 0.001$; Spearman's $\mathrm{r}=-0.540, \mathrm{p} \leq$ 0.001 ; respectively; fig. $4 \mathrm{~b}, \mathrm{c}$ ). In addition, correlations between cyp19 and foxl2 gene expression levels were also

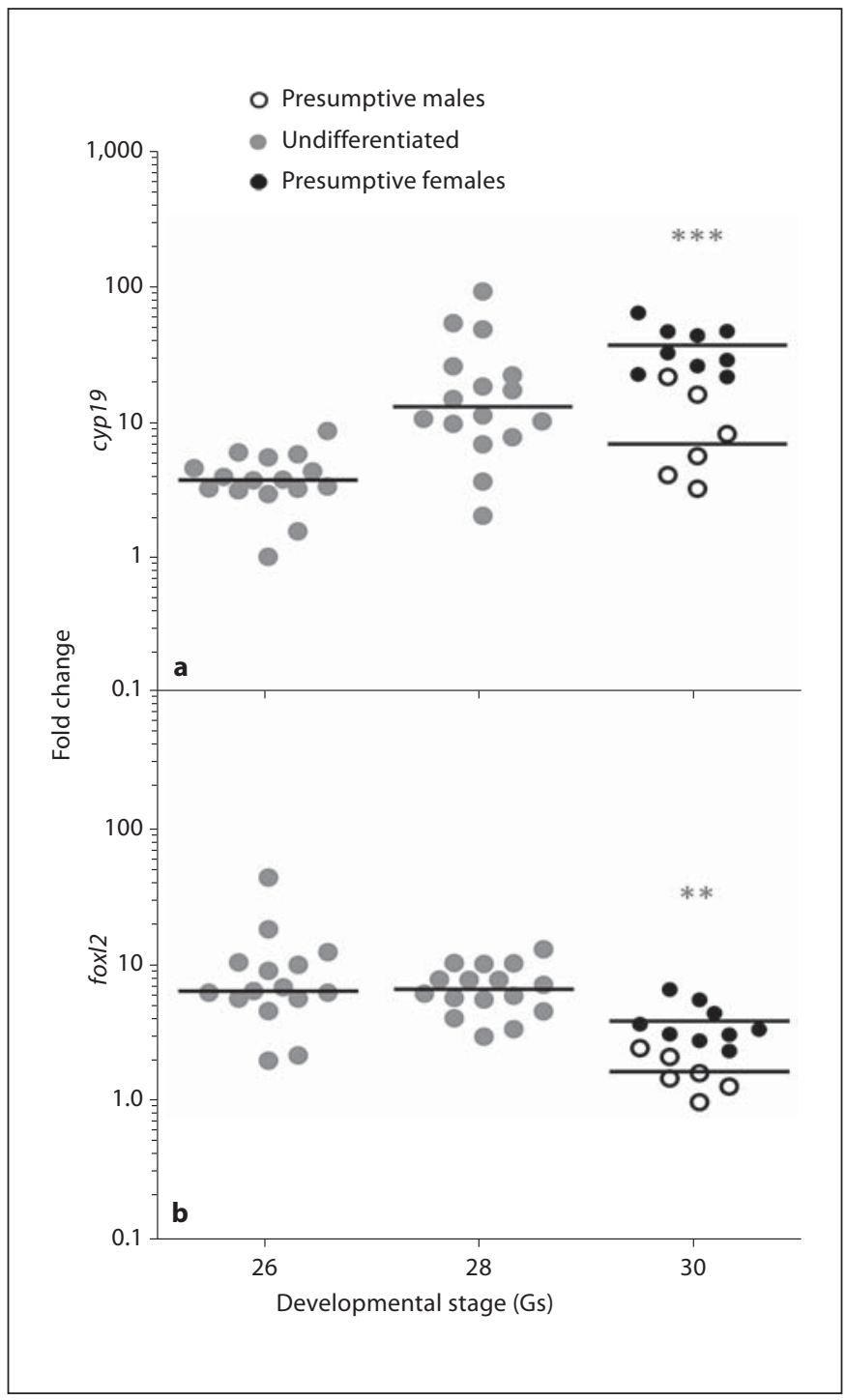

Fig. 3. Expression of cyp19 (a) and foxl2 (b) in the gonad-mesonephros complex of L. sylvaticus tadpoles during early metamorphosis. Animals at different Gs (Gs26, 28 and 30) were collected from a natural pond when the median stage in the pond was Gs26 $(n=16)$, Gs28 $(n=16)$ and Gs30 $(n=15)$, respectively. Data are presented as fold change in expression relative to the lowest sample value for each gene. A 2-step cluster analysis (where the number of clusters was not predetermined) using a combination of cyp19- and foxl2-fold change gene expression levels was carried out for each stage in order to classify tadpoles as undifferentiated, presumptive phenotypic females or presumptive phenotypic males (see Materials and Methods and Results sections for more details). Once classified, data were analyzed by a Student test. Bars represent the mean for each presumptive phenotypic sex. Significance is indicated by ${ }^{* *} \mathrm{p}<$ $0.005,{ }^{* *} \mathrm{p}<0.001$. 
Fig. 4. Relationship between cyp19, foxl2 and/or cyp17 expression in the GMC of $L$. sylvaticus tadpoles. a Correlation between cyp19 and foxl2 ( $\mathrm{r}=0.890, \mathrm{p} \leq 0.001)$. b $c y p 19$ and $c y p 17(\mathrm{r}=-0.641, \mathrm{p} \leq 0.001)$. c foxl2 and cyp $17(\mathrm{r}=-0.540, \mathrm{p} \leq 0.001)$ in the GMCs at Gs31-42. Due to lack of normality, data were analyzed by Spearman's correlation test. d Correlation between cyp19 and foxl2 in GMCs of Gs26 (open circles; $\mathrm{r}=0.451, \mathrm{p}=0.092$ ), Gs28 (grey circles; $\mathrm{r}=0.689, \mathrm{p}=0.003$ ) and Gs30 (black circles; $\mathrm{r}=0.907, \mathrm{p} \leq 0.001)$ using Pearson's correlation test. When analyzed together (Gs26, 28 and 30), no significant correlation was found between cyp19 and foxl2 $(\mathrm{r}=0.010, \mathrm{p}=0.946)$. All correlations were performed on an individual tadpole basis. Note that scales of the $y$-axis vary between genes.

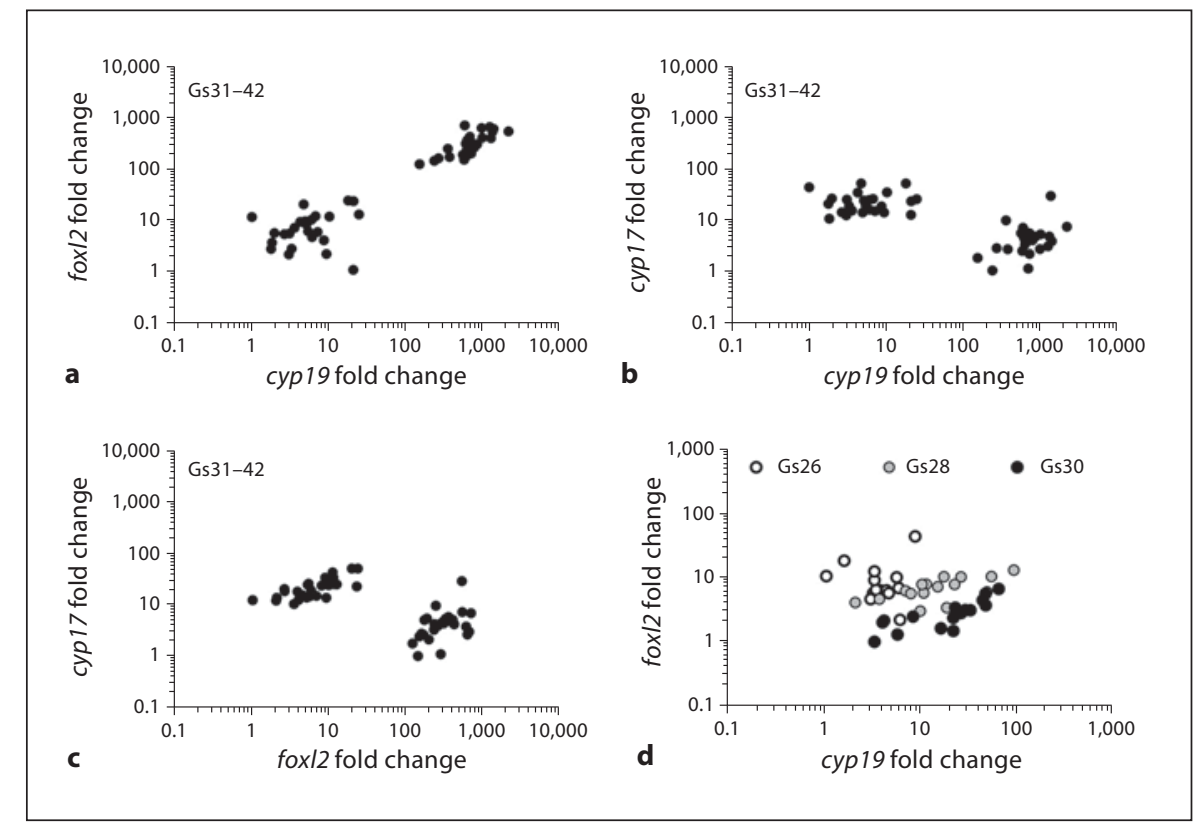

determined for Gs26, 28 and 30 samples (fig. 4d). No significant correlations were found when data from all 3 sampling periods were treated together (Pearson's $r=$ $0.100, p=0.946$ ). A different pattern emerged when correlations between cyp19 and foxl2 were tested separately at each developmental stage. There appeared to be no correlation between variables at Gs26 (Pearson's $r=0.451$, $\mathrm{p}=0.092)$. In contrast, a significant but weak correlation at Gs28 (Pearson's $r=0.689, \mathrm{p}=0.003$ ) and a strong significant correlation at Gs30 (Pearson's $\mathrm{r}=0.907, \mathrm{p} \leq$ 0.001 ) were evident between cyp19 and foxl2.

Clear Dimorphic cyp19 Gene Expression Levels in Developing S. tropicalis GMCs Are Predictive of Phenotypic Sex

Gene expression levels of cyp19 were measured in gonads of adult $S$. tropicalis males and females. Cluster analysis clearly confirmed that cyp19 gene expression levels in the adult females clustered together, while the male values were assigned to a second cluster (fig. 5). In addition, significant differences (Wilcoxon $\mathrm{W}=21.00, \mathrm{p}=0.004$ ) in cyp19 levels where found between adult testes and ovaries, with ovaries presenting approximately $10,000 \times$ more cyp19 expression than testes. This result supports the idea that cyp19 gene expression can be used as a female marker because ovaries have higher expression levels than testes. A 2-step cluster analysis was carried out for tadpole GMC at several developmental stages. Only one cluster was evident in the NF48 samples, but clearly dimorphic patterns were observed at NF50 and subsequent developmental stages (NF52-60), generating 2 well-differentiated clusters. All the NF48 tadpoles were assigned to the undifferentiated group while the 2 clusters generated from NF50 to 60 samples were assigned as presumptive phenotypic females and males. Individuals that clustered with the high cyp19 levels were designated as females (fig. 5). Significant differences $(\mathrm{p}<0.005)$ in cyp19 gene expression levels were found between presumptive phenotypic females and males at all developmental stages studied (NF50-60).

\section{Discussion}

Gender-Specific Patterns of cyp19, foxl2 and cyp17 Can Be Observed in L. sylvaticus Adult Gonads and Developing Tadpole GMCs

Our results show that expression of cyp19 was not detected in adult kidneys of either sex, but was clearly differentially expressed in ovaries versus testes. On the other hand, expression of foxl2 and cyp17 was detected in adult male and female kidneys, with no difference between sexes. When compared to testes and ovaries, foxl2 gene expression was found to be significantly lower in adult $L$. sylvaticus kidneys. In addition, kidney cyp 17 levels were significantly lower than levels in the testes, but were not different from ovaries. When studying gonadal differentiation in frogs, dissections of the tadpole GMC 
Fig. 5. Validation of cyp19 gonad-mesonephros expression as a marker of phenotypic sex using $S$. tropicalis tadpoles and adults. Gene expression of the cytochrome p450 aromatase (cyp19) was analyzed in the adult testes and ovaries as well as in the GMC of $S$. tropicalis tadpoles at different NF developmental stages. A 2-step cluster analysis (where the number of clusters was not predetermined) using cyp19-fold change gene expression levels was carried out for each stage in order to classify tadpoles as undifferentiated, presumptive phenotypic females or presumptive phenotypic males (see Materials and Methods and Results sections for more details). Once classified, differences between presumptive sexes within each stage were analyzed by Mann-Whitney's test. Bars represent the mean per each presumptive phenotypic sex. Significance is indicated by ** $\mathrm{p}<0.005$.

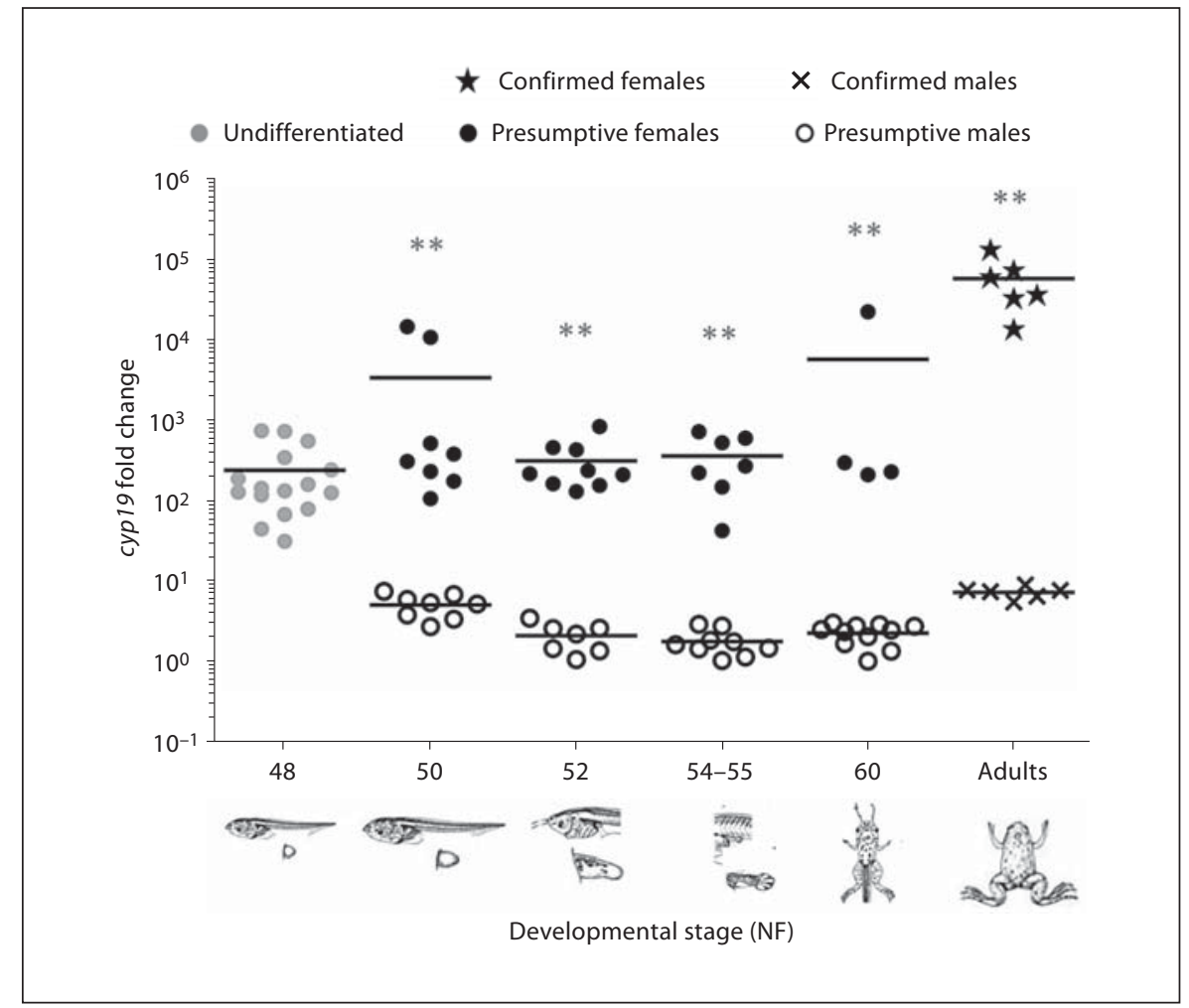

are commonly done to ensure sufficient amounts of mRNA. One possible critique is that the kidney-like tissues of the mesonephros may express levels of the studied genes that may interfere with data interpretation. However, this is not necessarily the case. Our results confirm that cyp19, foxl2 and cyp17 are expressed in a tissue-specific manner in adults, suggesting that in tadpoles the major contribution to GMC cyp19, foxl2 and cyp17 levels is from the developing gonadal tissues.

In the present study, dimorphic gene expression levels of cyp19, foxl2 and cyp17 in the GMC of developing tadpoles (Gs31-42) were observed. Statistical analysis of the expression levels of these genes revealed the existence of 2 obvious clusters, which were assigned to male and female groups. Several studies have shown that dimorphic patterns are also observed in the GMCs of other frog species. For example, genetic female tadpoles undergoing differentiation have significantly higher cyp19 gonadal expression than males in both G. rugosa [Ohtani et al., 2003; Maruo et al., 2008; Oshima et al., 2009] and X. laevis [Urbatzka et al., 2007] tadpoles. Similarly, foxl2 expression was found higher in the GMCs of developing genetic females than in genetic males of G. rugosa tadpoles [Oshima et al., 2008]. In contrast, adult males, sex

Using Aromatase Gene Expression as a Phenotypic Sex Marker in Frogs reversed male tadpoles and differentiating genetic male tadpoles express significantly higher gonadal levels of cyp17 than adult females or differentiating genetic female of G. rugosa tadpoles [Iwade et al., 2008; Maruo et al., 2008; Sakurai et al., 2008; Suda et al., 2011b]. Although genetic sex markers have not been established for many species, including $L$. sylvaticus, we can conclude that these 3 genes are good candidates for studying sex differentiation in frogs.

\section{Molecular Differentiation May Occur Earlier than Morphological Differentiation of the Gonads in L. sylvaticus Tadpoles}

Generally, in fish, the gonadal form of cyp19 (cyp19a1a) can be detected in the developing gonads even before morphological sex differentiation occurs [Nakamura et al., 1998; Baroiller et al., 1999; Blázquez et al., 2009], with aromatization taking place before sex differentiation and directing the fate of the gonad [Kwon et al., 2000]. Although histological analyses were not carried out in the present analysis, our results suggest that dimorphic patters in the GMC of L. sylvaticus tadpoles can be observed previous to morphological differentiation of the tadpole gonads. A study by Witschi [1929] determined that ovar- 
ian and testis differentiation can be first detected in 28-day-old L. sylvaticus tadpoles. Unfortunately, the age of the wild tadpoles collected for the present study is unknown, since we had no information about when fertilization or hatching occurred in the ponds. However, Witschi [1929] reported that the total length of the tadpoles of that age was around $30 \mathrm{~mm}$, and gonads of smaller tadpoles remained undifferentiated. Interestingly, and although all GMCs at Gs28 were classified as being undifferentiated, a significant but weak correlation between cyp19 and foxl2 levels was found. At that stage, total length of our L. sylvaticus tadpoles ranged from 17 to $23 \mathrm{~mm}$ (data not shown), suggesting that morphological differentiation of the gonads had not yet occurred. This could indicate that sex differentiation at the molecular level was just beginning at this stage of development. Cautious interpretation of these data are warranted, since somatic growth and development are both temperature-dependent and conditions might differ between studies. On the other hand, sex differentiation in tadpoles seems to be more influenced by age than by developmental stage [Ogielska and Kotusz, 2004; and pers. observations]. Our results show that for L. sylvaticus tadpoles of the same age, Gosner stage did not contribute to the classification of phenotypic sex. This result suggests that the lack of differences between $L$. sylvaticus gene expression levels at different stages (from Gs31 to 42) most likely indicates that gonadal differentiation in L. sylvaticus is also more dependent on age (and/or growth rate) rather than on metamorphic stage. Future studies are needed to determine if molecular differentiation occurs before or during morphological differentiation of the gonads in L. sylvaticus tadpoles. Furthermore, the developmental factors that drive the timing of gonadal differentiation in frogs remain unclear.

\section{Development of a Useful Tool to Determine}

Phenotypic Sex in Frogs Using Gonadal cyp19 Gene

Expression Levels

We carried out a discriminant analysis using gene expression levels in L. sylvaticus GMCs (Gs31-42) to determine the importance of the variables used to classify both presumptive males and females. This analysis revealed that all 3 genes clearly contribute to discriminate between groups (i.e. phenotypic sex), but that gene expression levels of cyp19 is a better predictor of phenotypic sex than foxl2, which is a better predictor than cyp17. In addition, the structure matrix correlations value for cyp 17 revealed that expression of cyp17 is a poor predictor. We, therefore, conclude that cyp19 gene expression levels in the L. syl- vaticus $\mathrm{GMC}$ is the best discriminating variable to assign phenotypic sex in L. sylvaticus. Furthermore, statistical analysis also revealed the existence of significant correlations between the analyzed genes, especially at later stages of development, when gonadal differentiation is taking place. These results reinforce the idea that cyp19 levels are sufficient to discriminate phenotypic sex during $L$. sylvaticus gonadal differentiation.

One of the aims of the present study was to develop a molecular method to identify phenotypic sex not only in species from the Ranidae family, but that also could be suitable for other frog species. Therefore, we decided to validate our method with one of the model species used in our laboratories, S. tropicalis, which belongs to the Pipidae family, estimated to have diverged approximately 135 mya from the Ranidae family [Zhang et al., 2005]. Duarte-Guterman and Trudeau [2011] showed clear dimorphic expression of cyp19 in the adult males and females gonads of $S$. tropicalis, with females showing significant higher expression levels (around $100 \times$ higher) than seen in males. In the same study, cyp19 levels in the GMC of developing tadpoles (from developmental stages NF52-66) were highly variable within each developmental stage, with some individuals presenting undetectable levels. Multiplex real-time RT-PCR reactions were carried out by Duarte-Guterman and Trudeau [2011], wherein the different primers compete to amplify different genes in the same reaction. These conditions could lead to some detection limitations resulting in undetectable levels of cyp19 in the GMC samples presenting very low expression levels. The authors suggested that the individuals with higher cyp19 levels could be presumptive females, whereas the ones with either very low or no cyp19 expression would most likely be presumptive males. In the present study, we have increased the number of $S$. tropicalis individuals analyzed, included earlier stages, and analyzed samples in single PCR reactions. Our results showed that although only one cluster was found in GMC samples at developmental stage NF48, clear dimorphic patterns were observed from NF50 onwards. A study carried out by El Jamil et al. [2008b] reported that the first signs of morphological differentiation of the testes in $S$. tropicalis appear at NF48, whereas signs of ovarian differentiation were first observed at NF51. They also showed that undifferentiated gonads could be found in tadpoles at developmental stages from NF45 to 52. In our study, we have demonstrated that the first dimorphic differences in cyp19 gene expression can be found as early as NF50, coinciding with the initiation of morphological differentiation of the gonads. Therefore, in S. tropicalis, cyp19lev- 
els are differentially expressed before the first signs of ovarian differentiation at NF51. In support of this observation, sexually dimorphic levels of GMC cyp19 in G. rugosa have been reported 2 weeks earlier than cyp17 and foxl2 [Ohtani et al., 2003; Iwade et al., 2008; Maruo et al., 2008; Oshima et al., 2008, 2009; Sakurai et al., 2008; Suda et al., 2011b]. Together, these results support the use of cyp19 as an early ovarian differentiation marker in amphibians, as has been proposed for fish [Fernandino et al., 2008; Blázquez et al., 2009].

\section{Role of cyp19 Is Conserved across Vertebrate Species}

Several studies have determined a critical role for the enzyme aromatase (Cyp19), during sex differentiation in several non-mammalian vertebrate species. For instance, dimorphic gonadal expression of cyp19 in favor of females has been identified in chicken embryos [Abinawanto et al., 1996]; ovarian development requires that genetically female embryos achieve a threshold level of cyp19 gene expression leading to aromatase-dependent estrogen production, whereas the absence of sufficient estrogen leads to the differentiation of the genetic female embryonic gonads into testes [Abinawanto et al., 1996]. Sexually dimorphic levels of cyp19 mRNA have also been found in the gonads of reptiles [Warner, 2011], fish [PaulPrasanth et al., 2011] and amphibians [Flament et al., 2011]. Many studies have focused on the involvement of Cyp19 in fish sex differentiation. Ovarian sex differentiation has been related to high expression and activity levels of cyp19ala that produce an increase in estrogen synthesis [Devlin and Nagahama, 2002]. In contrast, testicular differentiation in male teleost fish requires the suppression of cyp19a1a in gonads [Piferrer et al., 1994; Guiguen et al., 1999; Navarro-Martín et al., 2009], supporting the idea that cyp19ala expression is critical for ovarian differentiation. Studies in the newt Pleurodeles waltl, have also demonstrated that cyp19 downregulation is necessary for testicular development [Kuntz et al., 2003]. Moreover, cyp19 levels in female-to-male sex reversed developing gonads of $G$. rugosa were decreased after administration of testosterone [Kato et al., 2004]. In the present study, we have shown that the cloned L. sylvaticus cyp19 nucleotide sequence is highly conserved when compared to other frog and toads species (with identity values ranging from 77 to 96\%). In addition, and as it has been found in other frog species [Ohtani et al., 2003; Urbatzka et al., 2007; Maruo et al., 2008; Oshima et al., 2009; DuarteGuterman and Trudeau, 2011; Duarte-Guterman et al., 2012], dimorphic patterns of cyp19 gene expression in developing GMCs were found in tadpoles from 2 different frog families: the Pipidae (S. tropicalis) and the Ranidae (L. sylvaticus). This evidence supports the idea that the role of cyp19 during ovarian differentiation is also conserved in amphibians.

\section{Conclusion}

Evidence from several studies, including the present one, suggests that cyp19 plays an important role in amphibian ovarian differentiation. We have successfully cloned L. sylvaticus cyp19, foxl2, and cyp17 genes. In all cases, sexual dimorphic expression patterns had been observed in L. sylvaticus adult gonads and developing tadpole GMCs. In addition, our data support the development of a new method for determining phenotypic sex in frogs at the time of gonadal differentiation by analyzing cyp19 gene expression in tadpole GMC. The advantage of using this method is that histological studies are not required to determine phenotypic sex, so gonadal samples can be used for further molecular analysis. We propose this method as a tool to study the effects of endocrine disrupting chemicals on gonadal development and sex ratios.

\section{Acknowledgements}

We are grateful for the support of Jeff Houlahan and give thanks to Chris Edge (University of New Brunswick, Saint John, Canada) for helping with the wild wood frog tadpole collection. This study was funded by the NSERC Strategic Grants (to V.L.T), an NSERC-PGSD (to P.D.-G.) and the STAGE program of Environment Canada. Support from the University of Ottawa Research Chair in Neuroendocrinology (to V.L.T) is also acknowledged with appreciation.

References

Abinawanto, Shimada K, Yoshida K, Saito N: Effects of aromatase inhibitor on sex differentiation and levels of P45017alpha and P450arom messenger ribonucleic acid of gonads in chicken embryos. Gen Comp Endocrinol 102:241-246 (1996).

- Akatsuka N, Komatsuzaki E, Ishikawa A, Suzuki I, Yamane N, Miyata S: Expression of the gonadal p450 aromatase gene of Xenopus and characterization of the $5^{\prime}$-flanking region of the aromatase gene. J Steroid Biochem Mol Biol 96:45-50 (2005).

- Aoyama S, Shibata K, Tokunaga S, Takase M, Matsui K, Nakamura M: Expression of Dmrtl protein in developing and in sex-reversed gonads of amphibians. Cytogenet $\mathrm{Ge}$ nome Res 101:295-301 (2003). 
Baroiller JF, D'Cotta H: Environment and sex determination in farmed fish. Comp Biochem Physiol C Toxicol Pharmacol 130:399409 (2001).

-Baroiller JF, Guigen Y, Fostier A: Endocrine and environmental aspects of sex differentiation in fish. Cell Mol Life Sci 55:910-931 (1999).

-Blázquez M, Navarro-Martín L, Piferrer F: Expression profiles of sex differentiation-related genes during ontogenesis in the European sea bass acclimated to two different temperatures. J Exp Zool B Mol Dev Evol 312:686700 (2009).

- Bogart MH: Sex determination: a hypothesis based on steroid ratios. J Theor Biol 128:349357 (1987).

-Boggs AS, Botteri NL, Hamlin HJ, Guillette LG Jr: Endocrine disruption of reproduction in reptiles, in Norris DO, Lopez KH (eds): Hormones and Reproduction of Vertebrates: Reptiles, vol 3, pp 373-396 (Elsevier, Amsterdam 2011).

Burns RP, Burns R: Discriminant Analysis, Business Research Methods and Statistics Using SPSS, pp 589-608 (SAGE Publications Ltd, Cornwall 2009).

Devlin RH, Nagahama Y: Sex determination and sex differentiation in fish: an overview of genetic, physiological, and environmental influences. Aquaculture 208:191-364 (2002).

-Dorizzi M, Mignot TM, Guichard A, Desvages G, Pieau C: Involvement of oestrogens in sexual differentiation of gonads as a function of temperature in turtles. Differentiation 47: 9-17 (1991).

Duarte-Guterman P, Trudeau VL: Transcript profiles and triiodothyronine regulation of sex steroid- and thyroid hormone-related genes in the gonad-mesonephros complex of Silurana tropicalis. Mol Cell Endocrinol 331: 143-149 (2011).

Duarte-Guterman P, Ryan MJ, Trudeau VL: Developmental expression of sex steroid- and thyroid hormone-related genes and their regulation by triiodothyronine in the gonadmesonephros of a Neotropical frog, Physalaemus pustulosus. Gen Comp Endocrinol 177:195-204 (2012).

-El Jamil A, Kanhoush R, Magre S, Boizet-Bonhoure B, Penrad-Mobayed M: Sex-specific expression of sox9 during gonadogenesis in the amphibian Xenopus tropicalis. Dev Dyn 237:2996-3005 (2008a).

-El Jamil A, Magre S, Mazabraud A, Penrad-Mobayed M: Early aspects of gonadal sex differentiation in Xenopus tropicalis with reference to an antero-posterior gradient. J Exp Zool A Ecol Genet Physiol 309:127-137 (2008b).

- Fernandino JI, Hattori RS, Shinoda T, Kimura H, Strobl-Mazzulla PH, et al: Dimorphic expression of $d m r t 1$ and cyp19al (ovarian aromatase) during early gonadal development in Pejerrey, Odontesthes bonariensis. Sex Dev 2:316-324 (2008).
Flament S, Chardard D, Chesnel A, Dumond H: Sex determination and sexual differentiation in amphibians, in Norris DO, Lopez KH (eds): Hormones and Reproduction of Vertebrates: Amphibians, vol 2, pp 1-19 (Elsevier, Amsterdam 2011).

Gosner KL: A simplified table for staging anuran embryos and larvae. Herpetologica 16:183190 (1960).

Guiguen Y, Baroiller JF, Ricordel MJ, Iseki K, Mcmeel OM, et al: Involvement of estrogens in the process of sex differentiation in two fish species: The rainbow trout (Oncorhynchus mykiss) and a Tilapia (Oreochromis niloticus). Mol Reprod Dev 54:154-162 (1999).

- Isomura T, Haraguchi S, Miyamoto K, Tsutsui K, Nakamura Y, Nakamura M: Estrogen biosynthesis in the gonad of the frog Rana rugosa. Gen Comp Endocrinol 170:207-212 (2011).

Iwade R, Maruo K, Okada G, Nakamura M: Elevated expression of P450c17 (CYP17) during testicular formation in the frog. Gen Comp Endocrinol 155:79-87 (2008).

Kato T, Matsui K, Takase M, Kobayashi M, Nakamura M: Expression of P450 aromatase protein in developing and in sex-reversed gonads of the XX/XY type of the frog Rana rugosa. Gen Comp Endocrinol 137:227-236 (2004).

Kawano K, Furusawa S, Matsuda H, Takase M, Nakamura M: Expression of steroidogenic factor-1 in frog embryo and developing gonad. Gen Comp Endocrinol 123:13-22 (2001).

Koyano S, Ito M, Takamatsu N, Takiguchi S, Shiba T: The Xenopus Sox3 gene expressed in oocytes of early stages. Gene 188:101-107 (1997).

-Kuntz S, Chesnel A, Duterque-Coquillaud M, Grillier-Vuissoz I, Callier M, et al: Differential expression of $\mathrm{P} 450$ aromatase during gonadal sex differentiation and sex reversal of the newt Pleurodeles waltl. J Steroid Biochem Mol Biol 84:89-100 (2003).

- Kwon JY, Haghpanah V, Kogson-Hurtado LM, McAndrew BJ, Penman DJ: Masculinization of genetic female Nile tilapia (Oreochromis niloticus) by dietary administration of an aromatase inhibitor during sexual differentiation. J Exp Zool 287:46-53 (2000).

Lutz LB, Cole LM, Gupta MK, Kwist KW, Auchus RJ, Hammes SR: Evidence that androgens are the primary steroids produced by Xenopus laevis ovaries and may signal through the classical androgen receptor to promote oocyte maturation. Proc Natl Acad Sci USA 98:13728-13733 (2001).

-Mackenzie CA, Berrill M, Metcalfe C, Pauli BD: Gonadal differentiation in frogs exposed to estrogenic and antiestrogenic compounds. Environ Toxicol Chem 22:2466-2475 (2003).

Maruo K, Suda M, Yokoyama S, Oshima Y, Nakamura M: Steroidogenic gene expression during sex determination in the frog Rana rugosa. Gen Comp Endocrinol 158:87-94 (2008).
Mayer LP, Overstreet SL, Dyer CA, Propper CR: Sexually dimorphic expression of steroidogenic factor 1 (SF-1) in developing gonads of the American bullfrog, Rana catesbeiana. Gen Comp Endocrinol 127:40-47 (2002).

-Miura I, Ohtani H, Nakamura M, Ichikawa Y, Saitoh K: The origin and differentiation of the heteromorphic sex chromosomes $\mathrm{Z}, \mathrm{W}$, $\mathrm{X}$, and $\mathrm{Y}$ in the frog Rana rugosa, inferred from the sequences of a sex-linked gene, ADP/ATP translocase. Mol Biol Evol 15: 1612-1619 (1998).

Nakajima T, Takase M, Miura I, Nakamura M: Two isoforms of FTZ-F1 messenger RNA: molecular cloning and their expression in the frog testis. Gene 248:203-212 (2000).

- Nakamura M, Kobayashi T, Chang XT, Nagahama Y: Gonadal sex differentiation in teleost fish. J Exp Zool 281:362-372 (1998).

Nakamura M, Maruo K, Suda M, Oshima Y, Sakurai N: Steroidogenic gene expression during sex determination in the frog, Rana rugosa. Biol Reprod:154 (2008).

- Navarro-Martín L, Blázquez M, Piferrer F: Masculinization of the European sea bass (Dicentrarchus labrax) by treatment with an androgen or aromatase inhibitor involves different gene expression and has distinct lasting effects on maturation. Gen Comp Endocrinol 160:3-11 (2009).

Navarro-Martín L, Lanctôt C, Edge C, Houlahan J, Trudeau VL: Expression profiles of metamorphosis-related genes during natural transformations in tadpoles of wild Wood Frogs (Lithobates sylvaticus). Can J Zool 90: 1059-1071 (2012).

Nieuwkoop P, Faber J: Normal Table of Xenopus laevis (Daudin). (Garland Publishing, New York 1994).

Norris DO: Endocrine disruption of reproduction in amphibians, in Norris DO, Lopez KH (eds): Hormones and Reproduction of Vertebrates: Amphibians, vol 2, pp 203-211 (Elsevier, Amsterdam 2011).

Ogielska M, Kotusz A: Pattern and rate of ovarian differentiation with reference to somatic development in anuran amphibians. J Morphol 259:41-54 (2004).

Ohtani H, Miura I, Ichikawa Y: Role of aromatase and androgen receptor expression in gonadal sex differentiation of ZW/ZZ-type frogs, Rana rugosa. Comp Biochem Physiol C Toxicol Pharmacol 134:215-225 (2003).

-Okada E, Yoshimoto S, Ikeda N, Kanda H, Tamura K, et al: Xenopus W-linked DM-W induces foxl2 and cyp19 expression during ovary formation. Sex Dev 3:38-42 (2009).

-Osawa N, Oshima Y, Nakamura M: Molecular cloning of Dmrtl and its expression in the gonad of Xenopus. Zoolog Sci 22:681-687 (2005).

Oshima Y, Hayashi T, Tokunaga S, Nakamura M: Wnt4 expression in the differentiating gonad of the frog Rana rugosa. Zoolog Sci 22:689693 (2005). 
Oshima Y, Kato T, Wang D, Murakami T, Matsuda Y, et al: Promoter activity and chromosomal location of the Rana rugosa P450 aromatase (cyp19) gene. Zoolog Sci 23:79-85 (2006).

Oshima Y, Noguchi K, Nakamura M: Expression of $l h x 9$ Isoforms in the developing gonads of Rana rugosa. Zoolog Sci 24:798-802 (2007).

Oshima Y, Naruse K, Nakamura M: Regulation of cyp19 expression by Sox proteins in the frog, Rana rugosa. Biol Reprod 78:84-85 (2008).

Oshima Y, Naruse K, Nakamura Y, Nakamura M: Sox3: a transcription factor for cyp19 expression in the frog Rana rugosa. Gene 445: 38-48 (2009)

Ottinger MA, Dean K, McKernan M, Quinn MJ Jr: Endocrine disruption of reproduction in birds, in Norris DO, Lopez KH (eds): Hormones and Reproduction of Vertebrates: Birds, vol 4, pp 239-260 (Elsevier, Amsterdam 2011).

Paul-Prasanth B, Nakamura M, Nagahama Y: Sex determination in fishes, in Norris DO, Lopez KH (eds): Hormones and Reproduction of Vertebrates: Fishes, vol 1, pp 1-14 (Elsevier, Amsterdam 2011).

- Piferrer F, Zanuy S, Carrillo M, Solar II, Devlin RH, Donaldson EM: Brief treatment with an aromatase inhibitor during sex-differentiation causes chromosomally female salmon to develop as normal, functional males. J Exp Zool 270:255-262 (1994).

-Sakurai N, Maruo K, Haraguchi S, Uno Y, Oshima $\mathrm{Y}$, et al: Immunohistochemical detection and biological activities of CYP17 (P450c17) in the indifferent gonad of the frog Rana rugosa. J Steroid Biochem Mol Biol 112: 5-12 (2008).

Scheib D: Effects and role of estrogens in avian gonadal differentiation. Differentiation 23 Suppl:S87-S92 (1983).

Scherer G: Introduction: vertebrate sex determination and gonadal differentiation. Cell Mol Life Sci 55:821-823 (1999).
Semba K, SaitoUeno R, Takayama G, Kondo M: cDNA cloning and its pronephros-specific expression of the Wilms' tumor suppressor gene, WT1, from Xenopus laevis. Gene 175: 167-172 (1996).

Shibata K, Takase M, Nakamura M: The Dmrt1 expression in sex-reversed gonads of amphibians. Gen Comp Endocrinol 127:232241 (2002).

Suda M, Kodama M, Oshima Y, Yamamoto K, Nakamura Y, et al: Up-regulation of FSHR expression during gonadal sex determination in the frog Rana rugosa. Gen Comp Endocrinol 172:475-486 (2011a).

Suda M, Uno Y, Fujii J, Matsuda Y, Nakamura M: Isolation and characterization of the $C Y$ P17A1 gene and its processed pseudogene in Rana rugosa. Comp Biochem Physiol B Biochem Mol Biol 160:54-61 (2011b).

Sugita J, Takase M, Nakamura M: Expression of dax-1 during gonadal development of the frog. Gene 280:67-74 (2001).

Takase M, Nakajima N, Kawano K, Imura I, Nakamura M: Expression of orphan nuclear receptors FTZ-F1 and SF-1/Ad4BP in the developing gonad of frogs. Biol Reprod 60:195 (1999).

Takase M, Nakajima T, Nakamura M: FTZ-F1 alpha is expressed in the developing gonad of frogs. Biochem Biophys Acta 1494:195-200 (2000a).

Takase M, Noguchi S, Nakamura M: Two sox9 messenger RNA isoforms: isolation of cDNAs and their expression during gonadal development in the frog Rana rugosa. FEBS Lett 466:249-254 (2000b).

Urbatzka R, Lutz I, Kloas W: Aromatase, steroid5-alpha-reductase type 1 and type 2 mRNA expression in gonads and in brain of Xenopus laevis during ontogeny. Gen Comp Endocrinol 153:280-288 (2007).

Urbatzka R, Lorenz C, Lutz I, Kloas W: Expression profiles of LH beta, FSH beta and their gonadal receptor $\mathrm{mRNAs}$ during sexual differentiation of Xenopus laevis tadpoles. Gen Comp Endocrinol 168:239-244 (2010).
Vajda AM, Norris DO: Endocrine-active chemicals (EACs) in fishes, in Norris DO, Lopez $\mathrm{KH}$ (eds): Hormones and Reproduction of Vertebrates: Fishes, vol 1, pp 245-264 (Elsevier, Amsterdam 2011).

vom Saal FS: Sexual differentiation in litterbearing mammals: influence of sex of adjacent fetuses in utero. J Anim Sci 67:18241840 (1989).

Warner DA: Sex determination in reptiles, in Norris DO, Lopez KH (eds): Hormones and Reproduction of Vertebrates: Reptiles, vol 3, pp 1-38 (Elsevier, Amsterdam 2011).

Witschi E: Studies on sex differentiation and sex determination in amphibians I. Development and sexual differentiation of the gonads of Rana sylvatica. J Exp Zool 52:235265 (1929).

-Yamamura Y, Aoyama S, Oshima Y, Kato T, Osawa N, Nakamura M: Molecular cloning and expression in gonad of Rana rugosa $w t 1$ and fgf9. Zoolog Sci 22:1045-1050 (2005).

Yokoyama S, Oshima Y, Tokita J, Suda M, Shinozuka T, Nakamura M: Androgen receptor of the frog Rana rugosa: molecular cloning and its characterization. J Exp Zool A Ecol Genet Physiol 311:796-812 (2009).

Yoshimoto S, Okada E, Oishi T, Numagami R, Umemoto H, et al: Expression and promoter analysis of Xenopus DMRT1 and functional characterization of the transactivation property of its protein. Dev Growth Differ 48: 597-603 (2006).

Yoshimoto S, Okada E, Umemoto H, Tamura K, Uno Y, et al: A W-linked DM-domain gene, $D M-W$, participates in primary ovary development in Xenopus laevis. Proc Natl Acad Sci USA 105:2469-2474 (2008).

Zhang P, Zhou H, Chen YQ, Liu YF, Qu LH: Mitogenomic perspectives on the origin and phylogeny of living amphibians. Syst Biol 54: 391-400 (2005). 